\title{
Glyphosate-induced Delayed Pyloric Obstruction, Ulcer and Scar Changes
}

\author{
Jin Yong Hao, Tao Jiang and Xiao Jun Huang \\ Department of Gastroenterology, Lanzhou University Second Hospital, Lanzhou, Gansu, China
}

\begin{abstract}
Glyphosate is a widely used herbicide. Acute glyphosate poisoning is not uncommon, mostly caused by a large amount of glyphosate entering the human body in a short time, and the common reason is taking it accidently. The manifestations of acute stage are mainly gastrointestinal reactions. The patient in the present study took glyphosate accidently. In the acute stage, the patient presented with nausea and vomiting, but no gastrointestinal bleeding or perforation was found. Upper gastrointestinal obstruction occurred after two months. Endoscopy revealed no abnormalities in the esophagus, but revealed multiple gastric scar changes, and pyloric obstruction. In addition, active gastric ulcer was also observed. Therefore, the choice of gastric lavage method, avoidance of neutralising acid-base reactions, and the longterm use of acid suppression and mucosal protection therapy may have important therapeutic implications for the repair of gastric mucosa in such cases.
\end{abstract}

Key Words: Glyphosate, Ulceration, Pyloric obstruction.

How to cite this article: Hao JY, Jiang T, Huang XJ. Glyphosate-induced Delayed Pyloric Obstruction, Ulcer and Scar Changes. J Coll Physicians Surg Pak 2020; 30(08):868-870.

\section{INTRODUCTION}

Glyphosate is a herbicide developed by Monsanto in the United States. It is widely used in global agricultural product at present, and is extensively used in countryside of China. Glyphosate mainly inhibits 5-enolpyruvylshikimate-3-phosphate synthase in plants, which inhibits the conversion of shikimin into phenylalanine, tyrosine and tryptophan, interfering with protein synthesis and causing plant death. ${ }^{1}$ The toxic mechanism of glyphosate in mammals has been considered to be due to decoupling of oxidative phosphorylation in the energy metabolism pathway. ${ }^{2}$ At present, there are many reports of acute glyphosate poisoning. Treatment in acute stage includes gastric lavage, emergency endoscopic hemostasis, oral use of active carbon and egg white to absorb the glyphosate surfactant, and other therapeutic measures. ${ }^{3,4}$ The present study reports a patient who developed pyloric obstruction two months after taking glyphosate accidently.

Correspondence to: Xiao Jun Huang, Department of Gastroenterology, Lanzhou University Second Hospital, No. 82 of Linxia Street, Chengguan District, Lanzhou, 730030, China

E-mail: huangxj068@21cn.com

Received: April 26, 2019; Revised: September 30, 2019;

Accepted: October 14, 2019

DOI: https://doi.org/10.29271/jcpsp.2020.08.868

\section{CASE REPORT}

The patient was a 44-year woman, who was admitted to the General Surgery Department of our hospital due to history of accidental intake of glyphosate two months ago, and presenting with intermittent nausea and vomiting for half a month. Two months before admission, the patient took approximately $100 \mathrm{ml}$ of glyphosate accidently. After one hour, the patient presented with nausea and vomiting, and the vomit included a large amount of gastric contents and pesticides. Her family members look the patient to a local hospital. The patient was treated with mechanical gastric lavage in a local hospital; and the gastric lavage fluid used was clear water. After the lavage, the patient had no obvious nausea, vomiting, or other symptoms; and there were no gastrointestinal bleeding symptoms, such as hematemesis and melena. Hence, after 13 days of symptomatic treatment, the patient was discharged, and no discomforts, such as anorexia, nausea, sour regurgitation, heartburn, vomiting, hematemesis, melena, abdominal pain and diarrhea, occurred. At half a month before this admission, the patient presented with nausea and vomiting, without obvious inducement. The vomit contained gastric contents, but no hematemesis and melena was found. The patient did not vomit after taking a small amount of liquid diet. Then, the patient went to the Outpatient Department of our hospital, and was admitted due to upper gastrointestinal obstruction. During the course of the disease, the patient was conscious and oriented, with poor diet and sleep, but had normal urination, and defecated once every 3-4 days. The body weight of the patient decreased by approximately $12 \mathrm{~kg}$ in the past two months. The patient previously had good health, and had no history of peptic ulcer or any bad habits. 


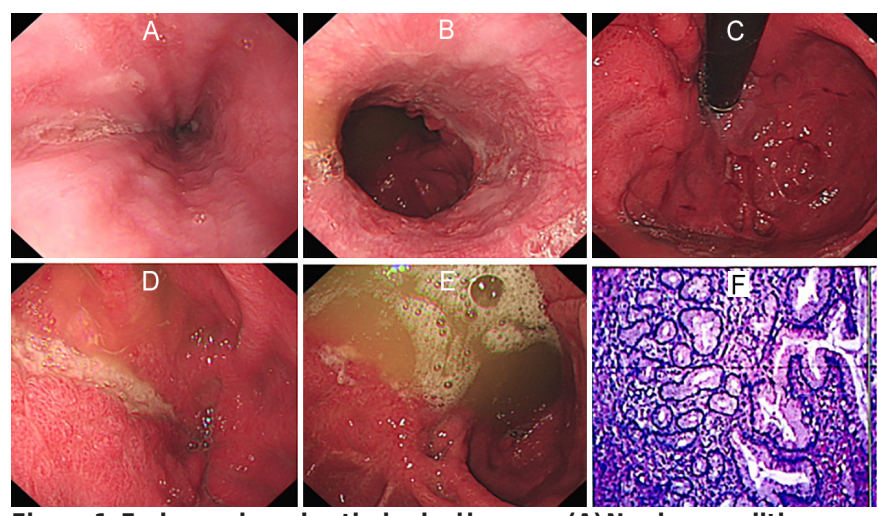

Figure 1: Endoscopic and pathological images. (A) No abnormalities were found in the middle esophagus under endoscopy. (B) No abnormalities were found in the lower esophagus underendoscopy. (C) Retroflex endoscopy revealed ulcer scar changes in the gastric cavity. (D) Corroded and deformed antrum with ulcer and invisible pylorus. (E) More retention fluid can be seen in the gastric body, and irregular scar traction changes of gastric mucosa. (F) Gastric antral ulcer biopsy showed acute on chronic cycle infection.

Physical examination: body temperature: $36.2^{\circ} \mathrm{C}$; pulse: 70 beats per minute (BPM); breathing: 20 times/min; blood pressure: 115/63 mmHg; mental status: lucid; bilateral pupils: 3.0 $\mathrm{mm}$ and light reflex: sensitive. No obvious cyanosis on the lips was found. The neck was soft, and no obvious swelling of superficiallymph nodes of neck was found. Both-sided lung respiratory sounds were clear, and there were no obvious dry and moist rales in both lungs. Pathological bruits were not heard in all valvular auscultation areas. The abdomen was flat and soft, and there was no tenderness and rebound pain in the abdomen. No obvious mass was felt. Bowel sounds were audible. Shifting dullness was negative. No obvious edema was found in the limbs.

In routine blood tests, leukocyte count was $3.24 \times 10^{9} / \mathrm{L}$, neutrophil percent was 0.49 , and lymphocyte, 0.43 . In routine stool test, the occult blood test was weakly positive. In routine urine test, occult blood was +1 , and urinary cholecystogen was $131 \mu \mathrm{mol} / \mathrm{L}$. In biochemistry tests, potassium was $3.00 \mathrm{mmol} / \mathrm{L}$, albumin was $33.4 \mathrm{~g} / \mathrm{L}$, globulin was $38.8 \mathrm{~g} / \mathrm{L}$, and the albumin-to-globulin ratio was 0.86 . In disseminated intravascular coagulation (DIC) test, D-dimer was $1.96 \mathrm{mg} / \mathrm{L}$, and the fibrinogen degradation product (FDP) was $6.3 \mu \mathrm{g} / \mathrm{ml}$.

On gastroscopy, no abnormality in the esophagus was found (Figure $1 \mathrm{~A} \& \mathrm{~B}$ ). Multiple ulcer scars could be observed in the stomach (Figure $1 \mathrm{C}$ ). The gastric cavity was deformed and contracted by mucosal traction. Longitudinal ulcers were observed in the greater curvature of the stomach body. The normal shapes of gastric antrum and pylorus were distorted, and a contracted outlet was observed (1D). The patient was diagnosed with pyloric obstruction (Figure 1E). In addition, biopsy was performed from the edge of the ulcer. The pathological examination showed lymphocytes, plasma cells and neutrophil infiltrations in the lamina propria. The histology results showed acute on chronic inflammation of gastric body (1F). The computed tomography (CT) abdomen revealed poor gastric filling, diffuse thickening of the gastric wall, and enlargement and enhancement of the third group of gastric lymph nodes. The patient underwent distal gastrectomy with gastrojejunostomy. The postoperative pathological examination showed mucosal surface erosions, glandular hyperplasia, and focal ulcer formation in some areas.

\section{DISCUSSION}

Although glyphosate is generally considered to be of low toxicity to humans, in 2015, the International Agency for Research on Cancer concluded it as carcinogenic. ${ }^{5}$ Long-term exposures to glyphosate may lead to kidney cell necrosis and leukemia, ${ }^{6}$ and may also lead to the occurrence of rare bacteremia. ${ }^{7}$ CNS depression, acute kidney injury, hepatic dysfunction, gastrointestinal mucosal damage, pancreatitis, electrolyte abnormalities, acidosis, acute respiratory distress syndrome (ARDS), hypotension, cardiovascular collapse, and death are all described. ${ }^{8-10}$ In the epidemiology of glyphosate poinsoning in Taiwan from 1986 to 2007, cardiovascular collapse and respiratory failure were found to be the two major causes of fatality. Intractable shock, especially hypovolemic shock, has been proposed to be the most important cause of fatality. In addition, noncardiogenic pulmonary edema or ARDS has been described as an important cause contributing to both respiratory failure and death. ${ }^{8}$ At present, herbicides on the market are mostly mixed preparations of glyphosate and other chemicals, making its toxicity higher, and its mechanism of poisoning more complicated. ${ }^{11}$

At present, treatments for acute glyphosate poisoning mainly include gastric lavage, inhibition of gastric acid, protection of mucosa, and other symptomatic treatments. Glyphosate is acidic diesel oil or laundry powder can enhance its medicinal properties, and its activity can be lost after complexing with $\mathrm{Ca}^{2+}$, $\mathrm{Mg}^{2+}$, and $\mathrm{Al}^{3+} .{ }^{12}$ In cases of severe glyphosate poisoning, such as development of ARDS, cardiovascular and respiratory compromise, extracorporeal membrane pulmonary oxygenation (ECMO) may be effective in the treatment. ${ }^{13,14}$

Occasional cases of esophageal perforation and death caused by glyphosate poisoning are reported. ${ }^{15}$ In the present case, no obvious abnormality was found in the esophagus during the whole course of treatment. The endoscopic images revealed that the fornix of the fundus of the stomach showed mostly round and concave scar marks and a longitudinal ulcer $(0.8 \times 3.5 \mathrm{~cm})$, and multiple longitudinal ulcer scars could be observed in the greater curvature of the stomach body. It was hypothesized that the site and shape of ulcer formation correlated to the site of accumulation of glyphosate in the gastric cavity.

The choice of gastric lavage method, avoidance of neutralising acid-base reactions with drugs such as sodium bicarbonate, and the long-term use of acid suppression and mucosal protection therapy may have important therapeutic implications for the repair of gastric mucosa. However, further observations are needed to determine whether the occurrence of complications caused by ulcer scars, such as gastric cavity deformation and pyloric obstruction, can be reduced by prolonging the time of acid suppression therapy, and increasing the dosage of acid suppression and mucosal protection drugs. 


\section{PATIENTS' CONSENT:}

Consent for publication was obtained from all individuals whose data are included in this manuscript.

\section{CONFLICT OF INTEREST:}

All authors have contributed significantly to the manuscript and declare that the work is original and has not been submitted or published elsewhere. None of the authors have any financial disclosure or conflict of interest.

\section{AUTHORS' CONTRIBUTION:}

JYH: Collected data and written manuscript.

TJL: Collected data and involved in written.

$\mathrm{XJH}$ : Edited and critically reviewed the manuscript.

\section{REFERENCES}

1. Mesnage R, Phedonos A, Biserni M, Arno M, Balu S, Corton $J C$, et al. Evaluation of estrogen receptor alpha activation by glyphosate-based herbicide constituents. Food Chem Toxicol 2017; 108(Pt A):30-42.

2. Bradberry SM, Proudfoot AT, Vale JA. Glyphosate poisoning. Toxicol Rev 2004; 23(3):159-67.

3. Liu SS, Mao XM. Two cases of pyloric obstruction caused by glyphosate poisoning. J Clin Emergency 2016; 0(6):489-91.

4. Stella J, Ryan M. Glyphosate herbicide formulation: A potentially lethalingestion. Emerg Med Australas 2004; 16(3):235-9.

5. Landrigan PJ, Belpoggi F. The need for independent research on the health effects of glyphosate-based herbicides. Environ Health 2018; 17(1):51.

6. Tarazona JV, Court-Marques D, Tiramani M, Reich H, Pfeil R, Istace $F$, et al. Glyphosate toxicity and carcinogenicity: A review of the scientific basis of the European Union assessment and its differences with IARC. Arch Toxicol 2017; 91(8):2723-43.

7. Kwiatkowska M, Jarosiewicz P, Michałowicz J, Koter-Michalak M, Huras B, Bukowska B. The impact of glyphosate, its metabolites and impurities on viability, atp level and morphological changes in human peripheral blood mononuclear cells. PLoS One 2016; 11(6):e0156946.

8. You MJ, Shin GW, Lee. CS clostridium tertium bacteremia in a patient with glyphosate ingestion. Am J Case Rep 2015; 16:4-7.

9. Chen YJ, Wu ML, Deng JF, Yang CC. The epidemiology of glyphosate-surfactant herbicide poisoning in Taiwan, 1986-2007: A poison center study. Clin Toxicol (Phila) 2009; 47(7):670-7.

10. Lee $\mathrm{CH}$, Shih $\mathrm{CP}$, Hsu KH, Hung DZ, Lin CC. The early prognostic factors of glyphosate-surfactant intoxication. Am J Emerg Med 2008; 26(3):275-81.

11. Moon JM, Chun BJ. Predicting acute complicated glyphosate intoxication in the emergency department. Clin Toxicol (Phila). 2010; 48(7):718-24.

12. Mertens M, Höss S, Neumann G, Afzal J, Reichenbecher W. Glyphosate: A chelating agent-relevant for ecological risk assessment? Environ Sci Pollut Res Int 2018; 25(6): 5298-5317.

13. Wang D, Zhang G, Zhang W, Luo J, Zhu L, Hu J. Successful extracorporeal membrane oxygenation support for severe acute diquat and glyphosate poisoning: A case report. Medicine (Baltimore) 2019; 98(6):e14414.

14. Chan CW, Wu IL, Lee CH, Hsu SC, Liao SC. Successful extracorporeal life-support in a case of severe glyphosatesurfactant intoxication. Crit Care Med. 2016; 44(1):e45-7.

15. Jyoti W, Thabah MM, Rajagopalan S, Hamide A. Esophageal perforation and death following glyphosate poisoning. J Postgrad Med 2014; 60(3):346-7. 